Reprinted from Journal of Applied Meteorology, Vol. 20, No. 11, November 1981 American Meteorological Society

Printed in U. S. A.

Convective Downmixing of Plumes in a Coastal Environment

Gregory J. McRae, Fredrick H. Shair and John H. Seinfeld 


\title{
Convective Downmixing of Plumes in a Coastal Environment
}

\author{
Gregory J. McRae, Fredrick H. Shair ${ }^{1}$ and John H. Seinfeld ${ }^{1}$ \\ Environmental Quality Laboratory, California Institute of Technology, Pasadena 91125
}

(Manuscript received 30 April 1981, in final form 2 August 1981)

\begin{abstract}
This paper describes the results of an atmospheric tracer study in which sulfur hexafluoride $\left(\mathrm{SF}_{6}\right)$ was used to investigate the transport and dispersion of effluent from a power plant located in a coastal environment. The field study demonstrated that material emitted into an elevated stable layer at night can be transported out over the ocean, fumigated to the surface, and then be returned at ground level by the sea breeze on the next day. At night when cool stable air from the land encounters the warmer ocean convective mixing erodes the stable layer forming an internal boundary layer. When the growing boundary layer encounters an elevated plume the pollutant material, entrained at the top of the mixed layer, can be rapidly transported in $\sim 20 \mathrm{~min}$ to the surface. Various expressions for the characteristic downmixing time $\left(\lambda=Z_{i} / w_{*}\right)$ are developed utilizing the gradient Richardson number, the MoninObukhov length and turbulence intensities. Calculations using these expressions and the field data are compared with similar studies of convective mixing over the land.
\end{abstract}

\section{Introduction}

A major influence on pollutant dispersion and transport in coastal environments is the presence of land/sea breeze circulation systems. Unfortunately the characterization of turbulent transport is complicated by the presence of flow reversals and differing atmospheric stabilities. Since many large sources are located in shoreline environments, it is important to understand the mixing characteristics within the boundary layer. A field experiment designed to determine the fate of pollutants emitted into the offshore flow associated with a land/sea breeze circulation system, was carried out by Shair et al. (1981). In that study it was found that tracer material emitted into an elevated stable layer at night could be transported out over the ocean, fumigated to the surface, and then be returned at ground level by the sea breeze on the next day. The objectives of this work are to examine the vertical transport processes responsible for this rapid downmixing and to characterize the mixing rates within the internal boundary layer formed when cool air from the land is advected out over a warm ocean surface.

\section{Description of field experiment}

Because of the complexity of atmospheric flows, the only direct way to relate the emissions from a particular source to observed concentrations is to tag the source exhaust gases so they can be uniquely identified. Over the last few years a variety of

${ }^{1}$ Department of Chemical Engineering. atmospheric tracers, including sulfur hexafluoride $\left(\mathrm{SF}_{6}\right)$, fluorescent particles, halocarbons and deuterated methane, have been used in transport and diffusion studies. Sulfur hexafluoride was used in this experiment because it is gaseous, physiologically inert, chemically stable, and easily detected using electron-capture gas chromatography (Simmonds et al., 1972). Drivas and Shair (1974), Lamb et al. (1978a,b) and Dietz and Cote (1973) have successfully demonstrated the utility of $\mathrm{SF}_{6}$ as a tracer in large-scale field studies. Current analysis techniques have achieved detection limits of $2 \times 10^{-13}$ parts $\mathrm{SF}_{6}$ per part of air. From a practical point of view both the release techniques and sampling protocols are well established and reliable.

Each experiment was carried out by injecting the tracer gas into the number 4 stack of the Southern California Edison El Segundo power plant located on the shore of Santa Monica Bay (Fig. 1). This particular chimney is $61 \mathrm{~m}$ high and $4.3 \mathrm{~m}$ in diameter. The tracer was released at a time when the flow, at the effective stack height, was offshore. Before each experiment an initial estimate of the plume rise was determined using Briggs' formulas (Briggs, $1969 ; 1975)$ for neutral conditions. For the particular load conditions ( 0.57 of capacity), an exhaust gas temperature of $365 \mathrm{~K}$ and a gas flow rate of $230 \mathrm{~m}^{3}$ $\mathrm{s}^{-1}$, the plume rise was estimated to be $250 \mathrm{~m}$. This information, together with the vertical wind distribution obtained from pibal releases, was used to establish the time to initate the tracer injection so that the material was released into the offshore flow. After the experiment a more detailed calculation, 


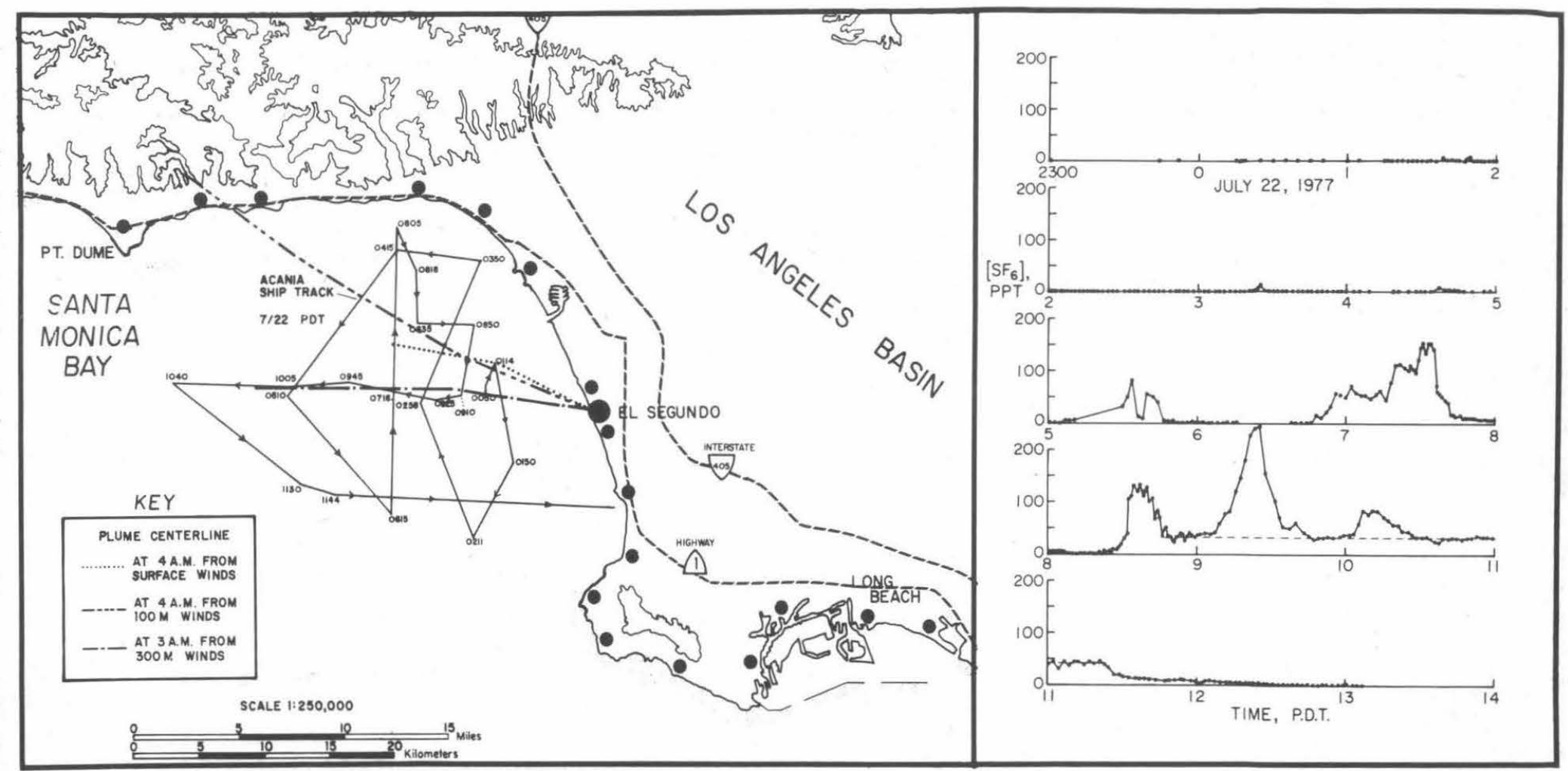

FIG. 1. Sulfur hexafluoride $\left(\mathrm{SF}_{6}\right)$ measurements made on board R/V Acania 22 July 1977 coordinated with ship course and possible plume trajectories derived from surface and elevated wind measurements: $(\bullet)$, release site; $(\bullet)$ onshore monitoring sites. 


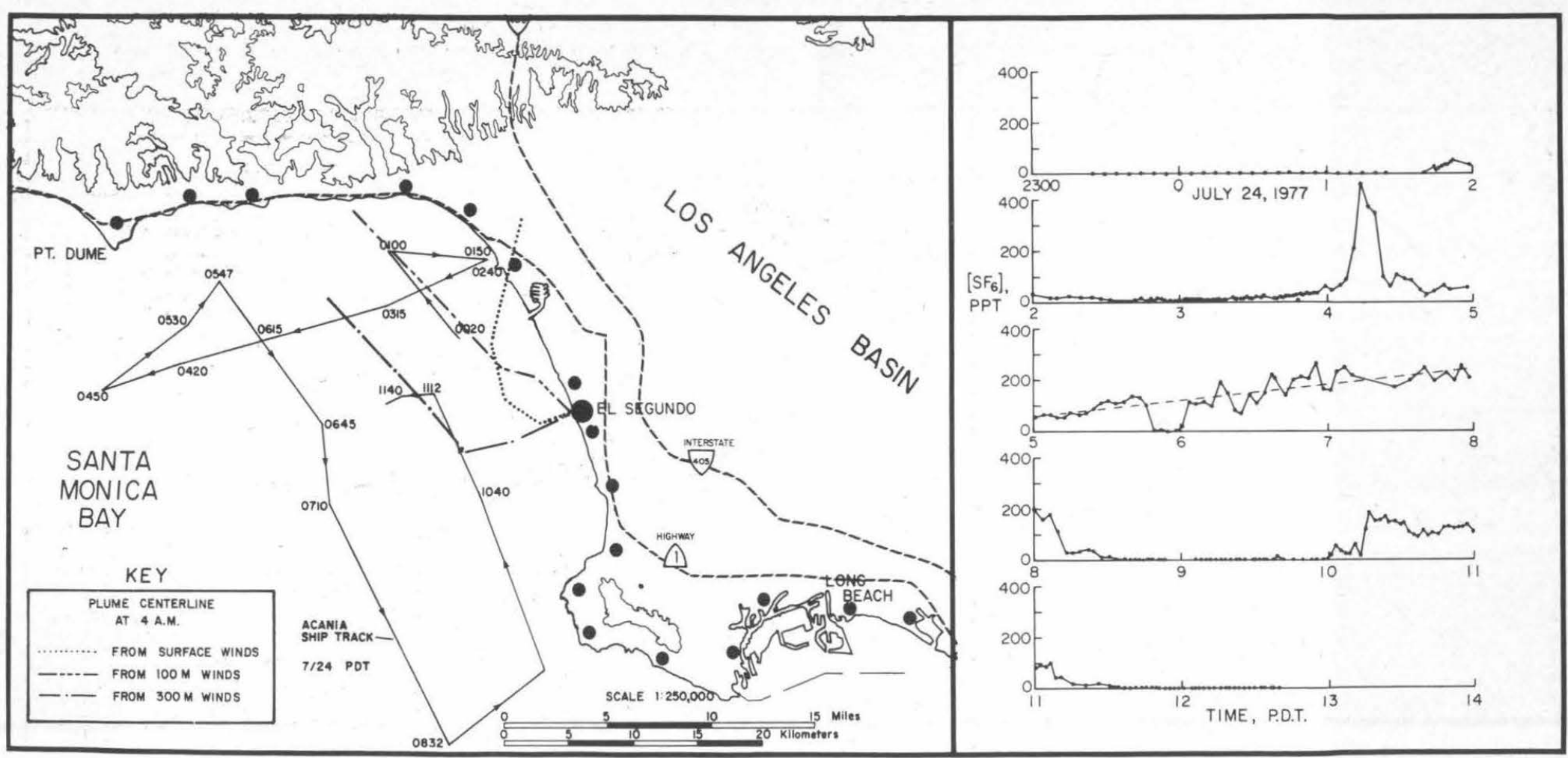

FIG. 2. Sulfur hexafluoride $\left(\mathrm{SF}_{6}\right)$ measurements made on board $\mathrm{R} / \mathrm{V}$ Acania 24 July 1977 coordinated with ship course and possible plume trajectories derived from surface and elevated wind measurements: $(\bullet)$ release site; $(\bullet)$ onshore monitoring sites. 
accounting for the actual vertical variations in wind and temperature profiles, was carried out using the Schatzmann (1979) integral plume rise model, using meteorological data from Schacher et al. (1978). During the first test, on 22 July $1977,90 \mathrm{~kg}$ of $\mathrm{SF}_{6}$ was released at a rate of $5.0 \mathrm{~g} \mathrm{~s}^{-1}$ from $0005-0500$ (all times PDT). During the second test $245 \mathrm{~kg}$ of $\mathrm{SF}_{6}$ were released, at a higher rate of $13.6 \mathrm{~g} \mathrm{~s}^{-1}$, from 2303 on 23 July 1977 until 0400 on 24 July.

The amount and release rates for each experiment were selected so that there was sufficient material to distinguish the source from the background at the maximum sampling distance. If the total amount of tracer released during each experiment were to be uniformly distributed throughout a volume of 1600 $\mathrm{km}^{2} \times 300 \mathrm{~m}$ (i.e., the area of Santa Monica Bay times the estimated plume rise above the ocean surface), then the average tracer concentration would have been $50 \mathrm{ppt}^{2}$, a value well above both the detection limit and normal background levels. Most of the current world background concentration of $<0.5 \mathrm{ppt}$ is a result of leakages from high-voltage power transformers and switching systems where $\mathrm{SF}_{6}$ is used for corona discharge suppression.

Hourly averaged air samples were collected continuously, from 0500-1700 during each of the test days, at 29 coastal sites located from Ventura to Corona del Mar (Figs. 1 and 2). This was to observe the tracer flux across the coast during the sea breeze on the day following the nighttime release. Subsequent mass balance calculations using these measurements were able to account for virtually $100 \%$ of the material released during both experiments (Shair et al., 1981). Samples were analyzed using the methodology described in Lamb et al. $(1978 \mathrm{a}, \mathrm{b})$. In addition, grab samples were collected every 5 min on board a ship traversing Santa Monica Bay and analyzed using portable electron-capture gas chromatographs. This sampling protocol provided rapid feedback on the tracer concentrations and plume position during each experiment. The measurements taken on board the ship are shown in Figs. 1 and 2. Sampling on board the ship was started $1 \mathrm{~h}$ before each release so that any possible background levels could be detected. All samples were collected in $30 \mathrm{~cm}^{3}$ plastic syringes and were analyzed within one day of each experiment. At the coastal monitoring sites battery-powered sequential samplers were used to determine the hourly averaged $\mathrm{SF}_{6}$ concentration levels. In addition automobile sampling traverses were conducted periodically along coastal highways between 1000-1427 on 22 July and between $0235-1540$ on 24 July. Grab samples were collected at $0.8-3.2 \mathrm{~km}$ intervals along the coastal highway between Redondo Beach and Malibu. The results from the shore measure-

\footnotetext{
${ }^{2}$ Parts per trillion.
}

ments and automobile traverses were used by Shair et al. (1981) to calculate the flux of $\mathrm{SF}_{6}$ across the coast.

The tracer experiments were carried out in collaboration with investigators from the Environmental Physics Group at the Naval Postgraduate School in Monterey, California. The research vessel Acania was used as a platform to collect meteorological data in the vicinity of Santa Monica Bay. The ship was equipped with a complete suite of meteorological equipment capable of multilevel measurements (4.2, 7.0 and $22.5 \mathrm{~m}$ above the ocean) of mean and fluctuating quantities. Since complete details of the instrumentation can be found in Houlihan et al. (1978) and Schacher et al. (1978), the material will not be repeated here. For the particular study of the mixing rates over the ocean, measurements were made of sea surface temperature $T_{s}$, air temperature $T_{a}$, humidity/dew point $T_{d}$, true wind speed $u$, direction $\theta$, and temperature inversion height $Z_{i}$. The wind direction $\theta$ is particularly useful since it can be used to differentiate local (land and sea breeze) circulations. Both the wind speed and direction have been corrected to account for the ship motion. In addition, during the period 19-26 July, 14 radiosondes were released to examine the vertical temperature structure. During each tracer experiment pibals were released each hour at a site close to the release point so that the horizontal winds as a function of elevation could be determined. Observations made at the 100 and $300 \mathrm{~m}$ levels were used to calculate plume trajectories from the release point. Some of these results are superimposed on Figs. 1 and 2. The complete data sets describing the meteorological conditions are contained in the reports by Schacher et al. $(1978,1980)$. For convenience a summary of key information from these sources, together with the calculated virtual heat flux $Q_{0}$, is presented in Table 1 .

Since the pattern of results observed on board R/V Acania on both days were similar it suffices to discuss the experiment conducted on 22 July. A more detailed discussion of the concentration levels measured at the coastal monitoring stations is contained in Shair et al. (1981). Prior to 0530 PDT, when the mixing depth was below $200 \mathrm{~m}$, the ship passed under the calculated plume positions at 0100,0325 and 0438 and no significant concentrations of $\mathrm{SF}_{6}$ were observed. At 0530 , when the ship was $6.4 \mathrm{~km}$ south of the plume, the first significant peak $(80 \mathrm{ppt})$ was recorded at a time when the mixed layer was growing above the $200 \mathrm{~m}$ level. From 0600 onward all the concentration peaks at 0730,0835 and 0925 were observed when the ship was in the vicinity of the plume and the mixed-layer height was above $200 \mathrm{~m}$. From 0830 to 1130 the $\mathrm{SF}_{6}$ exceeded $20 \mathrm{ppt}$ and the ship was always within $3 \mathrm{~km}$ of the plume. Lower concentrations were observed when the ship 
TABLE 1. Basic meterological data collected during the period 19-26 July 1977.*

\begin{tabular}{|c|c|c|c|c|c|c|c|c|c|c|c|c|c|}
\hline Date & $\begin{array}{l}\text { Time } \\
\text { (PDT) }\end{array}$ & $\begin{array}{l}\text { Humidity } \\
(\%)\end{array}$ & $\begin{array}{c}T_{a} \\
\left({ }^{\circ} \mathrm{C}\right)\end{array}$ & $\begin{array}{c}T_{s} \\
\left({ }^{\circ} \mathrm{C}\right)\end{array}$ & $\begin{array}{l}T_{a}-T \\
\left({ }^{\circ} \mathrm{C}\right)\end{array}$ & $\begin{array}{c}Q_{0} \\
\left(10^{3} \mathrm{~m} \mathrm{~s}^{-1} \mathrm{~K}\right)\end{array}$ & Date & $\begin{array}{l}\text { Time } \\
\text { (PDT) }\end{array}$ & $\begin{array}{c}\text { Humidity } \\
(\%)\end{array}$ & $\begin{array}{c}T_{a} \\
\left({ }^{\circ} \mathrm{C}\right)\end{array}$ & $\begin{array}{c}T_{3} \\
\left({ }^{\circ} \mathrm{C}\right)\end{array}$ & $\begin{array}{l}T_{\mathrm{a}}-T_{,} \\
\left({ }^{\circ} \mathrm{C}\right)\end{array}$ & $\begin{array}{c}Q_{0} \\
\left(10^{3} \mathrm{~m} \mathrm{~s}^{-1} \mathrm{~K}\right)\end{array}$ \\
\hline 19 & 0000 & 90 & 16.4 & 19.1 & -2.75 & 8.7 & 21 & 0945 & 89 & 17.5 & 18.8 & -1.26 & 2.8 \\
\hline 19 & 0020 & 92 & 16.0 & 18.5 & -2.53 & 5.6 & 21 & 1005 & 88 & 17.4 & 18.2 & -0.72 & 2.1 \\
\hline 19 & 0100 & 92 & 16.0 & 17.6 & -1.61 & 2.4 & 21 & 1025 & 88 & 17.6 & 18.5 & -0.38 & 0.8 \\
\hline 19 & 0140 & 93 & 15.9 & 16.7 & -0.80 & 0.7 & 21 & 1045 & 88 & 17.6 & 18.4 & -0.80 & 1.6 \\
\hline 19 & 1620 & 79 & 18.7 & 21.1 & -2.39 & 14.9 & 21 & 1105 & 89 & 17.4 & 17.7 & -0.33 & 2.1 \\
\hline 19 & 1650 & 79 & 18.5 & 21.1 & -2.57 & 19.4 & 21 & 1305 & 90 & 17.7 & 17.7 & -0.05 & 2.2 \\
\hline 19 & 1710 & 79 & 18.3 & 21.0 & -2.72 & 18.8 & 21 & 1325 & 90 & 17.5 & 17.7 & -0.24 & 3.0 \\
\hline 19 & 1730 & 79 & 18.1 & 20.9 & -2.77 & 19.4 & 21 & 1345 & 90 & 17.5 & 17.9 & -0.40 & 3.0 \\
\hline 19 & 2000 & 84 & 18.2 & 18.8 & -0.59 & 5.8 & 21 & 1405 & 90 & 17.7 & 18.2 & -0.54 & 4.6 \\
\hline 19 & 2040 & 87 & 17.5 & 19.8 & -2.26 & 11.8 & 21 & 1505 & 88 & 18.2 & 18.9 & -0.68 & 7.9 \\
\hline 19 & 2120 & 87 & $\quad 17.5$ & 19.8 & -2.26 & 7.3 & 21 & 1620 & 86 & 18.3 & 18.8 & -0.47 & 6.6 \\
\hline 19 & 2140 & 87 & 17.6 & 19.9 & -2.33 & 7.5 & 21 & 1720 & 85 & 18.0 & 18.7 & -0.69 & 6.4 \\
\hline \multirow[t]{2}{*}{19} & 2200 & 87 & 17.6 & 19.8 & -2.20 & 8.9 & 21 & 1945 & 79 & 18.6 & 19.9 & -1.30 & 10.4 \\
\hline & & & & & & & 21 & 2030 & 85 & 18.2 & 19.8 & -1.66 & 7.5 \\
\hline 20 & 0700 & 86 & 17.0 & 18.7 & -1.67 & 9.9 & 21 & 2110 & 84 & 18.3 & 19.7 & -1.35 & 3.4 \\
\hline 20 & 0740 & 86 & 17.3 & 19.2 & -1.93 & 8.5 & 21 & 2130 & 85 & 18.3 & 19.5 & -1.21 & 3.8 \\
\hline 20 & 0900 & 85 & 17.8 & 19.3 & -1.46 & 4.6 & & & & & & & \\
\hline 20 & 0920 & 85 & 17.9 & 19.3 & -1.42 & 4.4 & 22 & 0550 & 93 & 17.1 & 17.3 & -0.19 & 0.5 \\
\hline 20 & 1240 & 78 & 19.0 & 20.2 & -1.20 & 5.2 & 22 & 0610 & 94 & 16.9 & 17.2 & -0.34 & 0.7 \\
\hline 20 & 1300 & 79 & 19.0 & 19.8 & -0.78 & 3.2 & 22 & 0710 & 96 & 16.5 & 17.3 & -0.77 & 0.5 \\
\hline 20 & 1320 & 88 & 19.0 & 19.7 & -0.63 & 2.3 & 22 & 0730 & 97 & 16.6 & 17.3 & -0.68 & 0.4 \\
\hline 20 & 1800 & 84 & 18.8 & 18.2 & 0.56 & -3.9 & 22 & 0750 & 97 & 16.5 & 17.3 & -0.76 & 0.5 \\
\hline 20 & 1900 & 83 & 18.3 & 17.8 & 0.48 & -4.3 & 22 & 0810 & 97 & 16.7 & 17.3 & -0.57 & 0.3 \\
\hline 20 & 1920 & 84 & 18.4 & 17.7 & 0.65 & -6.4 & 22 & 0830 & 96 & 16.6 & 17.3 & -0.72 & 2.1 \\
\hline 20 & 1940 & 84 & 18.3 & 18.4 & -0.12 & 2.5 & 22 & 0910 & 97 & 16.5 & 17.3 & -0.78 & 1.4 \\
\hline 20 & 2000 & 85 & 18.2 & 18.3 & -0.09 & 2.1 & 22 & 0930 & 97 & 16.6 & 17.3 & -0.71 & 0.8 \\
\hline 20 & 2020 & 86 & 17.7 & 18.3 & -0.56 & 3.7 & 22 & 1030 & 96 & 17.1 & 18.5 & -1.46 & 4.6 \\
\hline 20 & 2040 & 87 & 17.9 & 18.3 & -0.45 & 2.5 & 22 & 1050 & 94 & 17.5 & 18.6 & -1.09 & 1.4 \\
\hline 20 & 2120 & 88 & 17.8 & 18.2 & -0.41 & 2.3 & & & & & & & \\
\hline 20 & 2140 & 89 & 17.7 & 18.2 & -0.53 & 2.8 & 23 & 1440 & 87 & 19.2 & 18.2 & 0.92 & -1.4 \\
\hline 20 & 2220 & 90 & 17.6 & 19.0 & -1.38 & 4.8 & 23 & 1505 & 85 & 19.5 & 18.7 & 0.76 & -2.9 \\
\hline 20 & 2230 & 91 & 17.6 & 18.4 & -0.83 & 2.7 & 23 & 1645 & 83 & 19.9 & 20.4 & -0.43 & 5.1 \\
\hline \multirow[t]{2}{*}{20} & 2300 & 91 & 17.2 & 18.2 & -1.00 & 2.9 & 23 & 1725 & 85 & 19.1 & 19.2 & -0.08 & 1.9 \\
\hline & & & & & & & 23 & 1745 & 87 & 18.8 & 19.1 & -0.28 & 1.2 \\
\hline 21 & 0000 & 94 & 16.6 & 17.2 & -0.63 & 2.5 & 23 & 2340 & 90 & 18.5 & 18.0 & 0.53 & -0.5 \\
\hline 21 & 0040 & 94 & 16.2 & 16.9 & -0.70 & 2.5 & & & & & & & \\
\hline 21 & 0100 & 93 & 15.9 & 16.6 & -0.72 & 2.0 & 24 & 0040 & 91 & 19.1 & 18.6 & 0.50 & -0.7 \\
\hline 21 & 0405 & 98 & 16.2 & 17.7 & -1.46 & 6.3 & 24 & 0100 & 90 & 19.0 & 18.6 & 0.39 & -0.5 \\
\hline 21 & 0425 & 97 & 16.4 & 18.1 & -1.65 & 6.2 & 24 & 0120 & 90 & 19.0 & 18.7 & 0.28 & -0.3 \\
\hline 21 & 0445 & 96 & 16.8 & 18.4 & -1.57 & 6.0 & 24 & 0240 & 87 & 19.0 & 18.7 & 0.25 & -0.3 \\
\hline 21 & 0505 & 94 & 17.1 & 18.4 & -1.33 & 4.5 & 24 & 0300 & 86 & 19.0 & 18.7 & 0.28 & -0.3 \\
\hline 21 & 0545 & 91 & 17.4 & 18.2 & -0.81 & 2.2 & 24 & 0420 & 88 & 18.8 & 18.7 & 0.06 & 0.0 \\
\hline 21 & 0605 & 89 & 17.4 & 18.3 & -0.84 & 0.7 & 24 & 1000 & 78 & 19.3 & 19.2 & 0.06 & 0.5 \\
\hline 21 & 0645 & 89 & 17.3 & 18.3 & -0.96 & 2.0 & & & & & & & \\
\hline 21 & 0705 & 89 & 17.3 & 18.2 & -0.86 & 2.4 & 25 & 2220 & 83 & 19.3 & 17.7 & 1.57 & -8.8 \\
\hline 21 & 0845 & 91 & 17.7 & 19.0 & -1.31 & 6.4 & 25 & 2320 & 84 & 19.1 & 17.9 & 1.27 & -7.1 \\
\hline 21 & 0905 & 89 & 17.8 & 18.9 & -1.14 & 3.9 & 26 & 0420 & 90 & 18.6 & 18.1 & 0.49 & -0.2 \\
\hline
\end{tabular}

* Source: Schacher et al. (1980).

and the plume separation increased to more than $15 \mathrm{~km}$. The only major difference between the two tests was the increased wind speeds and mixing heights on 23-24 July. While this, together with the wind shear, enhanced the horizontal dispersion of $\mathrm{SF}_{6}$ there were no significant differences in the observed vertical mixing rates.

Although the power plant effluent was emitted well above the surface into an elevated stable layer where vertical mixing could be expected to be quite small, large amounts of tracer suddenly appeared at the sampling sites close to the ocean surface. The remaining sections of this work are devoted to a discussion of the reasons for the rapid transport of tracer material to the surface.

\section{Vertical mixing over the ocean}

The problem of dispersion and transport near coastlines and large lakes has received considerable attention in the literature (See, e.g., Lyons, 1975; Businger, 1975; Misra, 1980; Raynor et al., 1980 Orgill, 1981). The purpose of this section is to examine the results from prior observations applicable to the present field experiment, since few, if any, studies have been made of convective activity over the ocean at night. Since the ocean temperatures during the experiments were greater than that of the air, it can be seen that the conditions are similar to those observed over the land during the day.

Under the action of buoyancy forces induced by 


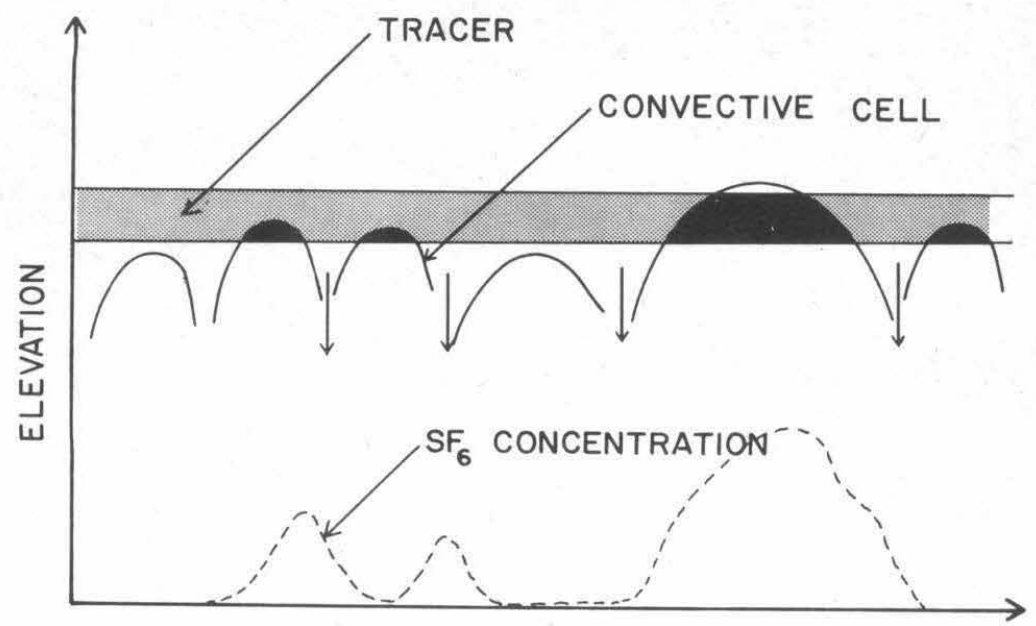

FIG. 3. Intermittent entrainment of tracer material by convective cells.

surface heating, parcels of warm air, displaced by mechanical turbulence, rise all the way through the mixed layer and impinge at the inversion base. To compensate for these vertical motions, zones of sinking air fill the spaces between rising air parcels. Close to the top of the mixed layer the net flux is directed downward. Adiabatic transport of air through the capping inversion would produce the negative flux, which in turn suggests a mechanism for substantial entrainment of air and tracer material into the mixed layer from above (Ball, 1960; Kaimal et al., 1976; Deardorff et al., 1980). The regions of upward flux are obviously thermals which originate near the surface shear layer and the transport is thus occurring over a scale $Z_{i}$.

The updraft regions in the thermals resembles the three-dimensional convection patterns observed by Frisch et al. (1975) with dual-Doppler radar. Kaimal et al. (1976) suggested that the rising air spreads out laterally as it reaches the inversion base, producing a domelike depression at the interface, and returns as a downdraft along the "side wall" of the thermal. These structures can be observed with acoustic sounders and radars. Arnold et al. (1975) found that domelike structures are colocated with the thermals detected simultaneously by an acoustic sounder. The strong returns from the side walls indicate the presence of entrained air from the inversion. The inverted $U$ structures in the vertical section and the doughnut-shaped patterns in plan views observed by Hardy and Ottersten (1969), Konrad (1970), Arnold and Rowland (1976) and Agee and Chen (1973) in radar returns indicate the presence of convective cells.

Arnold and Rowland (1976) conclude that most of the entrainment takes place along the top of the dome. Here either the Kelvin-Helmholtz instability or wavelike overturning of the dome structures could provide the mechanism for entrainment. This process is illustrated in Fig. 3 where the tops of the convective cells can rise to the elevation of the $\mathrm{SF}_{6}$. Entrainment of this material and its subsequent transport to the surface lead to the large concentration increases. Areas of low concentration would then result when the ship went beyond the bounds of the cloud or when the convective cells did not reach the height of the tracer. A detailed examination of the mechanism of entrainment and mixedlayer growth is beyond the scope of this work and for details the reader is referred to Stull (1973), Venkatram (1976), Zeman and Tennekes (1977), Heidt (1977) and Deardorff (1978). Convective entrainment has been studied in the laboratory by Willis and Deardorff (1976a), Manins (1977) and Deardorff et al. (1980). The characteristic separation distance of the thermals given by Kaimal et al. (1976) is $1.3-1.4 Z_{i}$ with the diameter-to-depth ratio for the Rayleigh cells being of the order of $40: 1$ (Agee and Chen, 1973).

With this background it is now possible to advance an explanation of the findings from the tracer experiments. When the cool stable air from the land encounters the warmer ocean surface, convective mixing begins to erode the overlying stable layer forming an internal boundary layer (Fig. 4). (The growth of this layer as a function of distance from the shore can be seen in the acoustic sounder traces.) Convective mixing in the surface layer entrains air from the stable layer aloft causing the inversion base to rise from the surface. Heating of the mixed layer is due to the combined effects of an upward heat flux from the ocean and a downward flux from the warmer air in the inversion. Continued growth of the mixed layer ultimately leads to a situa- 


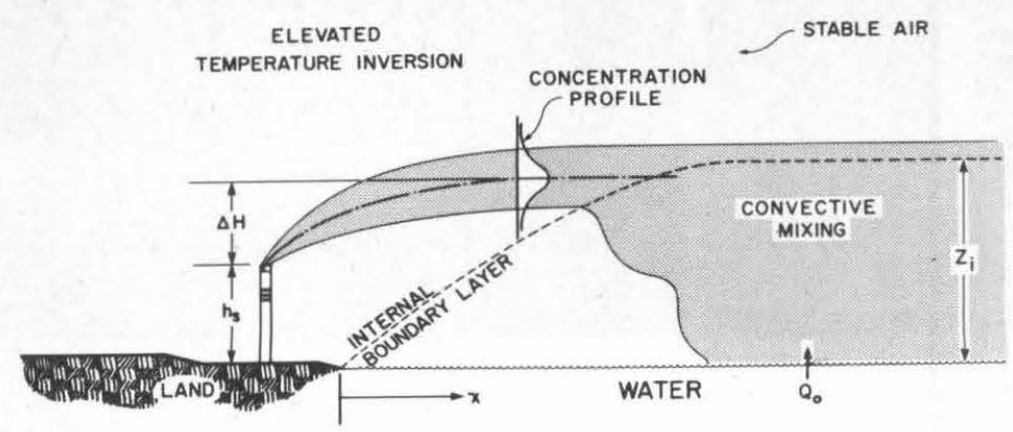

(a)

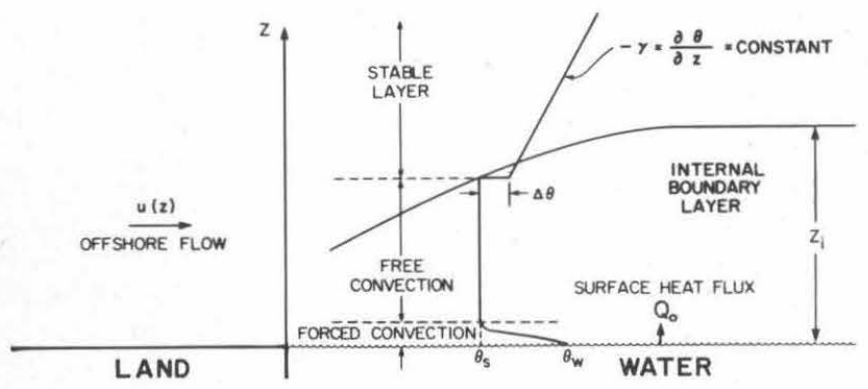

(b)

FIG. 4. Schematic representation of (a) fumigation process and (b) notation for mixing model.

tion where the internal boundary layer intercepts the elevated plume and the tracer materials. Since below the inversion base the mixing is rapid, the entrained $\mathrm{SF}_{6}$ is quickly transported to the surface. Except for the strength of the convective mixing, the conditions of the experiment are similar to those that occur over the land during the day. Subsequent sections of this work are devoted to an estimate of the rate at which the tracer material is transported to the surface.

\section{Mixing times under convective conditions}

Under convective conditions a variety of interacting processes are involved in the mixing within the boundary layer. The relative role of buoyancy $\overline{w^{\prime} T_{v}{ }^{\prime}}$, in comparison with the transfer of energy from the mean motion $\overline{u^{\prime} w^{\prime}} \partial \bar{u} / \partial z$, can be expressed in terms of the flux Richardson number $\mathbf{R}_{f}$ (Monin and Yaglom, 1971; Kraus, 1972), as

$$
\mathrm{R}_{f}=\frac{\frac{g}{T} \overline{T_{v}^{\prime} w^{\prime}}}{\overline{u^{\prime} w^{\prime}} \frac{\partial \bar{u}}{\partial z}},
$$

where $T_{v}$ is the virtual temperature. A more commonly used expression is the gradient Richardson number Ri

$$
\mathrm{Ri}=\frac{g\left(\frac{\partial \bar{T}_{v}}{\partial z}+\Gamma\right)}{T_{v}\left(\frac{\partial \bar{u}}{\partial z}\right)^{2}}=\frac{g}{\theta_{v}} \frac{\frac{\partial \bar{\theta}_{v}}{\partial z}}{\left(\frac{\partial \bar{u}}{\partial z}\right)^{2}}=\frac{N^{2}}{\left(\frac{\partial \bar{u}}{\partial z}\right)^{2}},
$$

where $N$ is the Brunt-Väisälä frequency, $\theta_{v}$ the potential temperature, and $\Gamma$ the adiabatic lapse rate. The relationship between $\mathrm{R}_{f}$ and the more easily measured Richardson number $\mathrm{Ri}$ is simply $\mathrm{R}_{f}=\alpha \mathrm{Ri}$, where $\alpha$ is the ratio of the turbulent eddy diffusion coefficients for heat and momentum. Under a spatial homogeneity assumption temporal changes in the total mean kinetic energy are negligible if synoptic and mesoscale forces driving the boundary layer vary slowly (Caughey et al., 1978). In particular, if the time scales for the largescale processes are long compared to the time required for the boundary layer to adjust then the rate of change of turbulent kinetic energy per unit mass is negligible. If the contribution from the flux divergence term in the energy equation is small, 
TABLE 2. Additional data and calculated results for period 19-26 July 1977.*

\begin{tabular}{|c|c|c|c|c|c|c|c|c|c|}
\hline Date & $\begin{array}{c}\text { Time } \\
\text { (PDT) }\end{array}$ & $\begin{array}{c}u \\
\left(\mathrm{~m} \mathrm{~s}^{-1}\right)\end{array}$ & $\stackrel{\theta}{(\mathrm{K})}$ & $Z_{i} / L$ & $\begin{array}{c}u_{*} \\
\left(\mathrm{~m} \mathrm{~s}^{-1}\right)\end{array}$ & $\begin{array}{l}T_{*} \\
(\mathrm{~K})\end{array}$ & $\begin{array}{c}Z_{i} \\
(\mathrm{~m})\end{array}$ & $\begin{array}{c}w_{*} \\
\left(\mathrm{~m} \mathrm{~s}^{-1}\right)\end{array}$ & $\underset{(\min )}{\lambda}$ \\
\hline 19 & 0000 & 1.5 & 283 & -4.840 & 0.060 & -0.117 & 280 & 0.436 & 11 \\
\hline 19 & 0020 & 1.0 & 308 & -8.206 & 0.044 & -0.104 & 330 & 0.397 & 14 \\
\hline 19 & 0100 & 0.5 & 317 & -18.190 & 0.025 & -0.075 & 320 . & 0.296 & 18 \\
\hline 19 & 0140 & 0.3 & 11 & -29.206 & 0.014 & -0.035 & 190 & 0.166 & 19 \\
\hline 19 & 1620 & 3.1 & 294 & -1.125 & 0.112 & -0.077 & 470 & 0.585 & 13 \\
\hline 19 & 1650 & 3.9 & 272 & -0.754 & 0.142 & -0.085 & 500 & 0.663 & 13 \\
\hline 19 & 1710 & 3.6 & 275 & -0.929 & 0.132 & -0.093 & 490 & 0.659 & 12 \\
\hline 19 & 1730 & 3.7 & 285 & -0.889 & 0.136 & -0.096 & 480 & 0.665 & 12 \\
\hline 19 & 2000 & 4.4 & 277 & -0.216 & 0.156 & -0.023 & 500 & 0.477 & 17 \\
\hline 19 & 2040 & 3.0 & 280 & -1.134 & 0.108 & -0.082 & 540 & 0.597 & 15 \\
\hline 19 & 2120 & 1.5 & 5 & -4.174 & 0.060 & -0.092 & 590 & 0.525 & 19 \\
\hline 19 & 2140 & 1.5 & 318 & -4.291 & 0.060 & -0.096 & 600 & 0.534 & 19 \\
\hline 20 & 0700 & 3.6 & 285 & -0.542 & 0.129 & -0.051 & 160 & 0.369 & 7 \\
\hline 20 & 0740 & 2.5 & 260 & -1.433 & 0.089 & -0.068 & 230 & 0.400 & 10 \\
\hline 20 & 0900 & 1.5 & 250 & -2.852 & 0.058 & -0.053 & 160 & 0.290 & 9 \\
\hline 20 & 0920 & 1.5 & 250 & -2.502 & 0.058 & -0.044 & 180 & 0.286 & 10 \\
\hline 20 & 1240 & 2.0 & 195 & -1.645 & 0.071 & -0.036 & 360 & 0.385 & 16 \\
\hline 20 & 1300 & 1.8 & 206 & -1.459 & 0.064 & -0.020 & 360 & 0.332 & 18 \\
\hline 20 & 1320 & 2.0 & 220 & -0.773 & 0.069 & -0.013 & 280 & 0.264 & 18 \\
\hline 20 & 1800 & 7.2 & 186 & 0.045 & 0.259 & 0.036 & 80 & & \\
\hline 20 & 1900 & 6.2 & 275 & 0.079 & 0.213 & 0.042 & 140 & & \\
\hline 20 & 1920 & 7.2 & 250 & 0.058 & 0.257 & 0.041 & 160 & & \\
\hline 20 & 1940 & 7.2 & 270 & -0.004 & 0.267 & 0.013 & 260 & 0.069 & \\
\hline 20 & 2000 & 5.7 & 270 & -0.024 & 0.203 & 0.007 & 280 & 0.228 & 20 \\
\hline 20 & 2020 & 5.1 & 270 & -0.056 & 0.183 & -0.001 & 240 & 0.273 & 15 \\
\hline 20 & 2040 & 3.6 & 280 & -0.158 & 0.123 & -0.005 & 200 & 0.248 & 13 \\
\hline 20 & 2120 & 3.6 & 270 & -0.150 & 0.123 & -0.005 & 240 & 0.258 & 15 \\
\hline 20 & 2140 & 3.5 & 260 & -0.186 & 0.120 & -0.009 & 240 & 0.272 & 15 \\
\hline 20 & 2220 & 2.0 & 280 & -1.606 & 0.071 & -0.048 & 340 & 0.378 & 15 \\
\hline 20 & 2230 & 2.0 & 290 & -0.931 & 0.069 & -0.023 & 340 & 0.305 & 19 \\
\hline 20 & 2300 & 2.3 & 302 & -0.356 & 0.080 & -0.030 & 300 & 0.328 & 15 \\
\hline 21 & 0000 & 2.6 & 255 & -0.470 & 0.087 & -0.020 & 280 & 0.288 & 16 \\
\hline 21 & 0040 & 2.6 & 259 & -0.441 & 0.087 & -0.019 & 310 & 0.290 & 18 \\
\hline 21 & 0100 & 1.8 & 305 & -0.876 & 0.063 & -0.019 & 200 & 0.227 & 15 \\
\hline 21 & 0120 & 1.0 & 141 & -1.656 & 0.039 & -0.014 & 270 & 0.193 & 23 \\
\hline 21 & 0405 & 3.1 & 85 & -0.595 & 0.108 & -0.048 & 240 & 0.370 & 11 \\
\hline 21 & 0425 & 2.5 & 125 & -1.106 & 0.088 & -0.058 & 320 & 0.406 & 13 \\
\hline 21 & 0445 & 2.6 & 142 & -0.994 & 0.090 & -0.054 & 380 & 0.425 & 15 \\
\hline 21 & 0505 & 2.1 & 125 & -1.443 & 0.073 & -0.049 & 360 & 0.380 & 16 \\
\hline 21 & 0545 & 1.5 & 160 & -1.497 & 0.056 & -0.025 & 455 & 0.319 & 24 \\
\hline 21 & 0605 & 0.2 & 160 & -43.572 & 0.012 & -0.031 & 460 & 0.213 & 36 \\
\hline 21 & 0645 & 1.0 & 100 & -3.625 & 0.040 & -0.030 & 480 & 0.310 & 26 \\
\hline 21 & 0705 & 1.5 & 100 & -1.691 & 0.055 & -0.026 & 460 & 0.326 & 23 \\
\hline 21 & 0845 & 3.1 & 95 & -0.583 & 0.108 & -0.040 & 475 & 0.457 & 17 \\
\hline 21 & 0905 & 2.1 & 91 & -1.158 & 0.072 & -0.032 & 430 & 0.368 & 19 \\
\hline 21 & 0945 & 1.0 & 129 & -4.270 & 0.041 & -0.040 & 360 & 0.310 & 19 \\
\hline 21 & 1005 & 1.5 & 135 & -1.164 & 0.055 & -0.014 & 310 & 0.252 & 21 \\
\hline 21 & 1025 & 0.2 & 200 & -39.449 & 0.012 & -0.024 & 300 & 0.176 & 28 \\
\hline 21 & 1045 & 0.8 & 235 & -3.474 & 0.033 & -0.015 & 280 & 0.212 & 22 \\
\hline 21 & 1105 & 3.6 & 270 & -0.035 & 0.120 & 0.006 & 260 & 0.143 & 30 \\
\hline 21 & 1305 & 7.2 & 258 & 0.006 & 0.264 & 0.012 & 180 & & \\
\hline 21 & 1325 & 7.0 & 260 & 0.000 & 0.256 & 0.009 & 210 & & \\
\hline 21 & 1345 & 6.5 & 280 & -0.003 & 0.237 & 0.008 & 200 & 0.079 & 42 \\
\hline 21 & 1405 & 6.7 & 285 & -0.020 & 0.246 & 0.000 & 200 & 0.244 & 14 \\
\hline 21 & 1505 & 6.5 & 280 & -0.045 & 0.240 & -0.007 & 200 & 0.318 & 10 \\
\hline 21 & 1620 & 7.0 & 260 & -0.021 & 0.260 & 0.003 & 200 & 0.258 & 13 \\
\hline 21 & 1720 & 5.5 & 270 & -0.058 & 0.198 & -0.003 & 120 & 0.239 & 8 \\
\hline 21 & 1945 & 4.0 & 250 & -0.397 & 0.144 & -0.038 & 250 & 0.428 & 10 \\
\hline 21 & 2030 & 2.5 & 225 & -1.328 & 0.089 & -0.059 & 150 & 0.336 & 7 \\
\hline 21 & 2110 & 1.0 & 220 & -5.585 & 0.042 & -0.053 & 300 & 0.325 & 15 \\
\hline 21 & 2130 & 1.5 & 220 & -2.618 & 0.056 & -0.043 & 310 & 0.341 & 15 \\
\hline 22 & 0550 & 2.0 & 130 & -0.209 & 0.065 & 0.000 & 205 & 0.143 & 24 \\
\hline 22 & 0610 & 1.5 & 130 & -0.550 & 0.053 & -0.006 & 220 & 0.169 & 22 \\
\hline 22 & 0710 & 0.2 & 140 & -35.247 & 0.012 & -0.030 & 240 & 0.157 & 26 \\
\hline
\end{tabular}


TABLE 2. (Continued)

\begin{tabular}{|c|c|c|c|c|c|c|c|c|c|}
\hline 22 & 0730 & 0.2 & 120 & -29.493 & 0.012 & -0.024 & 240 & 0.144 & 28 \\
\hline 22 & 0810 & 0.2 & 150 & -21.592 & 0.011 & -0.015 & 245 & 0.126 & 33 \\
\hline 22 & 0830 & 2.1 & 180 & -0.631 & 0.070 & -0.018 & 230 & 0.238 & 16 \\
\hline 22 & 0910 & 1.0 & 307 & -2.365 & 0.040 & -0.024 & 210 & 0.205 & 17 \\
\hline 22 & 1050 & 0.5 & 305 & -10.055 & 0.024 & -0.033 & 260 & 0.213 & 20 \\
\hline 23 & 1440 & 2.5 & 250 & 1.332 & 0.050 & 0.031 & 280 & & \\
\hline 23 & 1505 & 3.9 & 215 & 0.285 & 0.114 & 0.039 & 310 & & \\
\hline 23 & 1645 & 4.6 & 275 & -0.086 & 0.163 & 0.001 & 320 & 0.307 & 17 \\
\hline 23 & 1725 & 4.9 & 262 & -0.011 & 0.170 & 0.012 & 355 & 0.112 & \\
\hline 24 & 0120 & 1.5 & 236 & 0.767 & 0.037 & 0.014 & 170 & & \\
\hline 24 & 0240 & 1.7 & 140 & 0.381 & 0.046 & 0.016 & 120 & & \\
\hline 24 & 0300 & 1.5 & 136 & 0.455 & 0.041 & 0.016 & 160 & & \\
\hline 24 & 0420 & 1.0 & 210 & 0.044 & 0.032 & 0.011 & 140 & & \\
\hline 24 & 1000 & 1.0 & 269 & -0.091 & 0.034 & 0.021 & 165 & & \\
\hline 25 & 2220 & 5.0 & 270 & 0.340 & 0.150 & 0.068 & 160 & & \\
\hline 25 & 2320 & 5.0 & 280 & 0.231 & 0.157 & 0.054 & 160 & & \\
\hline 26 & 0420 & 1.4 & 340 & 3.147 & 0.019 & 0.012 & 90 & & \\
\hline
\end{tabular}

* Source: Schacher et al. (1980).

then, with the above assumptions, the turbulent kinetic energy equation reduces to

$$
-\overline{u^{\prime} w^{\prime}} \frac{\partial \bar{u}}{\partial z}\left(1-\mathrm{R}_{f}\right)-\epsilon=0,
$$

where $\epsilon$ is the dissipation or the rate of conversion of kinetic into internal energy by the viscous forces in the smallest eddies. Since $\epsilon>0$ and $-\overline{u^{\prime} w^{\prime}} \partial \bar{u} / \partial z$ is practically always greater than zero, stationary, undamped turbulence is possible only if $\mathrm{R}_{f}<1$. This result is often used as an approximate criterion for defining the transition to turbulence in a stratified medium. For the purpose of analyzing the experimental results within this framework it is useful to identify the appropriate length and velocity scales. A key scaling parameter is the Monin-Obukhov length $L$ defined by

$$
\begin{aligned}
\frac{1}{L} & =-\frac{k g Q_{0}}{u_{*}{ }^{3} T} \\
& =-\frac{k g}{u_{*}{ }^{3} T}\left(Q+0.61 \frac{T M_{0}}{\rho}\right)=\frac{1}{L_{T}}+\frac{1}{L_{q}},
\end{aligned}
$$

where $Q_{0}=\left(\overline{T_{v}{ }^{\prime} w^{\prime}}\right)_{0}$ is the virtual surface heat flux that accounts for the influence of humidity fluctuations on buoyancy, $k$ the von Kármán constant, $u_{*}{ }^{2}=-\overline{u^{\prime} w^{\prime}}$ the friction velocity, and $L_{T}$ and $L_{q}$ are the Monin-Obukhov lengths calculated from the surface heat and evaporative fluxes. Physically, $L$ is the height at which the two production terms are approximately of equal magnitude. One of the major differences in examining conditions over the ocean or other large bodies of water is that the density stratification is controlled not only by the surface heat flux but also by the water vapor flux. The measurements made by McBean and MacPherson (1975) over Lake Ontario indicate that there can be a significant difference between $L_{q}$ and $L_{T}$, that in turn have a major influence on $L$.

Above the surface layer a more appropriate length scale for the eddies is the mixed layer depth $Z_{i}$. While there is some controversy associated with a formal definition of $Z_{i}$, in this work it is defined as the elevation of the lowest inversion base. The studies of Deardorff (1972) and Deardorff et al. (1980) indicate that this is an appropriate boundary layer height for momentum and heat. Under convective conditions the appropriate velocity scale, above the surface layer, is given by

$$
\begin{aligned}
w_{*} & =\left(\frac{g}{T} Z_{i} Q_{0}\right)^{1 / 3} \\
= & {\left[\frac{g}{T} Z_{i}\left(\overline{w^{\prime} T_{v}{ }^{\prime}}\right)_{0}\right]^{1 / 3}=\left(-\frac{1}{k} \frac{Z_{i}}{L}\right)^{1 / 3} u_{*} . }
\end{aligned}
$$


The characteristic time scale under convective conditions is then given by $\lambda=Z_{i} / w_{*}$. Willis and Deardorff (1976b) have shown that material released instantaneously at the surface becomes nearly well mixed within a travel time of $\sim 3 \lambda$. In the field experiment the tracer material was "released" at the top of the mixed layer. Apart from the small contribution due to mechanical mixing the characteristic mixing time can be expected to be similar to that for a surface release. The reason for this is that the effective aerodynamic roughness of the ocean is very small.

There are a variety of means of estimating the fluxes needed to evaluate the above expressions. Three of the more common techniques are 1) the profile or gradient method, 2) the variance budget or dissipation technique, 3) and bulk aerodynamic calculations using air-sea differences. Schacher et al. $(1978,1980)$ employed the latter approach in reducing the meteorological data from the field experiment. A detailed discussion of these and other procedures is presented in Busch (1977). The key results from Schacher et al. $(1978,1980)$ are summarized in Table 2. In particular the frequency distribution of convective mixing times observed during the period 19-23 July is shown in Fig. 5 together with a similar distribution for daytime conditions over the land. The characteristic mixing times for both experiments were very similar. The influence of a much larger surface heat flux during the day is readily apparent.

In the surface layer, the velocity distribution can be expressed in terms of Monin-Obukhov similarity theory as

$$
\frac{\partial \bar{u}}{\partial z}=\frac{u_{*}}{k z} \phi_{m}\left(\frac{z}{L}\right),
$$

where $\phi_{m}$ is an experimentally determined function that corrects for the effects of buoyancy on turbulence. Businger et al. (1971) have constructed expressions for momentum $\phi_{m}$ and heat $\phi_{h}$ from an analysis of field data. For unstable conditions $z / L$ $<0$ the formulas are given by

$$
\begin{aligned}
\phi_{m}\left(\frac{z}{L}\right) & =\left[1-15\left(\frac{z}{L}\right)\right]^{-1 / 4}, \\
\phi_{h}{ }^{2}\left(\frac{z}{L}\right) & =\phi_{m}\left(\frac{z}{L}\right) .
\end{aligned}
$$

These results, together with (3), the definition of $u_{*}$ and the relation $\mathrm{Ri}=\alpha R_{f}$, can combined to give

$$
u_{*}{ }^{3}=\frac{k z}{(1-\alpha \mathrm{Ri}) \phi_{m}\left(\frac{z}{L}\right)} .
$$

The characteristic mixing time $\tau_{m}$ can be defined

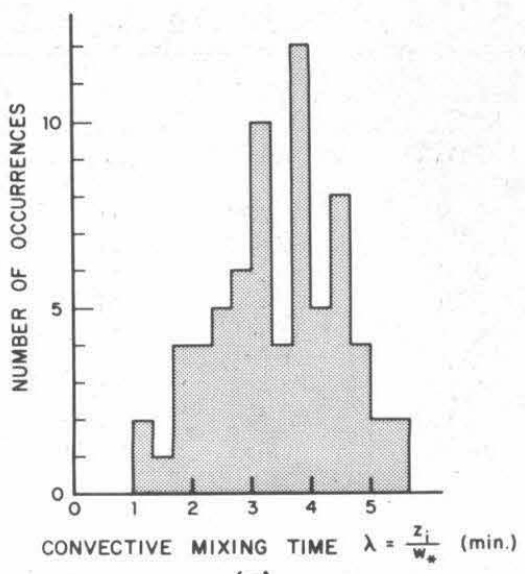

(a)

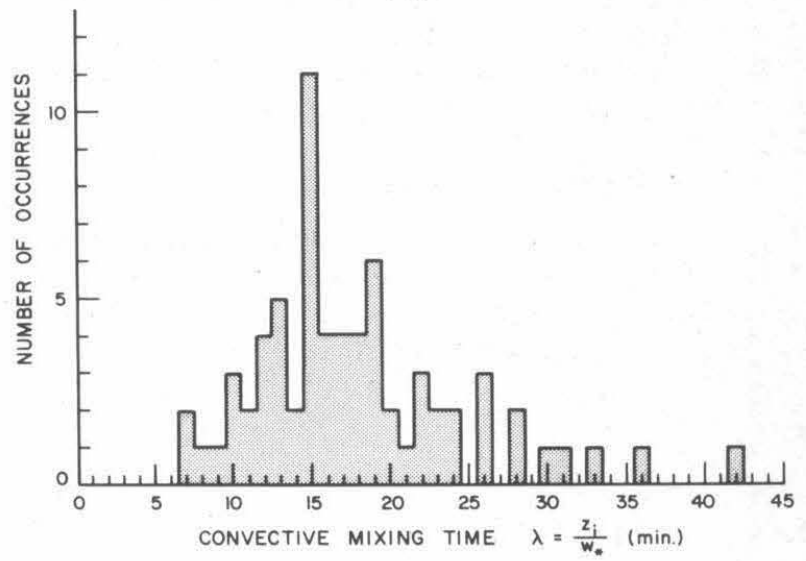

(b)

FIG. 5. Distribution of convective mixing times for (a) daytime conditions over land (source, Smithet al., 1976) and (b) nighttime conditions over ocean.

in terms of the convective time scale $\lambda$ as $\tau_{m}=3 \lambda$ $=3 Z_{i} / w_{*}$. Using (5), and the expression $\phi_{m} \mathbf{R}_{f}$ $=z / L$, Eq. (9) can be manipulated to give an estimate of the mixing time in terms of the measured dissipation rate and gradient Richardson number $\mathrm{Ri}$ :

$$
\tau_{m}=3\left[\frac{Z_{i}{ }^{2}}{\epsilon}\left(1-\frac{1}{\alpha \mathrm{Ri}}\right)\right]^{1 / 3} .
$$

For near-neutral conditions, Businger et al. (1971) determined that $\alpha=1.35$; thus a simple upper bound on (10) is $\tau_{m} \approx 3\left[-Z_{i}{ }^{2} / \epsilon \mathrm{Ri}\right]^{1 / 3}$. For unstable conditions when $|\mathrm{Ri}| \gg 1$, a lower bound is given by $\phi_{m}=3\left[Z_{i}^{2} / \epsilon\right]^{1 / 3}$. Using the data tabulated in Appendix B of Schacher et al. (1978) the limits on the convective mixing times can be calculated and are shown in Table 3 for the experiment conducted on 22 July. The important result from the tracer experiments is that the calculated mixing rates using 
TABLE 3. Convective mixing times based on turbulence intensities for 22 July 1977.

\begin{tabular}{|c|c|c|c|c|c|c|c|c|}
\hline Date & $\begin{array}{c}\text { Time } \\
\text { (PDT) }\end{array}$ & $Z_{i} / L$ & $\begin{array}{c}u_{*} \\
\left(\mathrm{~m} \mathrm{~s}^{-1}\right)\end{array}$ & $\begin{array}{c}Z_{i} \\
(\mathrm{~m})\end{array}$ & $\mathrm{Ri}$ & $\left(10^{-4} \mathrm{~m} \mathrm{~s}^{-3}\right)$ & $\begin{array}{l}{\left[\frac{Z_{i}^{2}}{\epsilon}\right]^{1 / 3}} \\
(\mathrm{~min})\end{array}$ & $-\underset{(\mathrm{min})}{\left.-\frac{Z_{i}^{2}}{\epsilon \mathrm{Ri}}\right]^{1 / 3}}$ \\
\hline 22 & 0550 & -0.209 & 0.065 & 205 & -0.04 & 1.8 & 10 & 30 \\
\hline 22 & 0610 & -0.550 & 0.053 & 220 & -0.09 & 3.6 & 8 & 19 \\
\hline 22 & 0710 & -35.247 & 0.012 & 240 & -0.16 & 3.6 & 9 & 17 \\
\hline 22 & 0730 & -29.493 & 0.012 & 240 & -0.08 & 4.0 & 9 & 20 \\
\hline 22 & 0750 & -32.846 & 0.012 & 240 & -0.18 & 2.9 & 10 & 17 \\
\hline 22 & 0810 & -21.592 & 0.011 & 245 & -0.21 & 5.1 & 8 & 14 \\
\hline 22 & 0830 & -0.631 & 0.070 & 230 & -0.10 & 4.6 & 8 & 17 \\
\hline 22 & 0910 & -2.365 & 0.040 & 210 & -0.02 & 7.1 & 7 & 24 \\
\hline 22 & 0930 & -6.285 & 0.023 & 220 & -0.03 & 7.3 & 7 & 22 \\
\hline
\end{tabular}

either the bulk or dissipation methods produces results consistent with the observed fumigation times. The rapid concentration increases were measured during times when the ship was beneath the plume and the mixed layer height exceeded $200 \mathrm{~m}$.

\section{Eddy diffusion coefficients}

A basic problem with modeling convectively driven flows is that the turbulent mixing is no longer described by local concentration gradients. Nevertheless, there are some circumstances in which it is desirable to parameterize the diffusive fluxes by a

$$
\frac{K_{z z}}{w_{*} Z_{i}}= \begin{cases}2.5\left(\frac{k z}{Z_{i}}\right)^{4 / 3}\left[1-15\left(\frac{z}{L}\right)\right]^{1 / 4}, & 0<\frac{z}{Z_{i}} \leqslant 0.05 \\ 0.021+0.408\left(\frac{z}{Z_{i}}\right)+1.352\left(\frac{z}{Z_{i}}\right)^{2}-4.096\left(\frac{z}{Z_{i}}\right)^{3}+2.560\left(\frac{z}{Z_{i}}\right)^{4}, & 0.05<\frac{z}{Z_{i}} \leqslant 0.6 \\ 0.2 \exp \left[6-10\left(\frac{z}{Z_{i}}\right)\right], & 0.6<\frac{z}{Z_{i}} \leqslant 1.1 \\ 0.0013, & \frac{z}{Z_{i}}>1.1 .\end{cases}
$$

As can be seen from Fig. 6 the maximum value of the diffusivity occurs when $z / Z_{i} \approx 0.5$ and has a magnitude $\sim 0.21 w_{*} Z_{i}$. For typical conditions this corresponds to a diffusion time, defined by $Z_{i}{ }^{2} / K_{z z}$, of $\sim 5 Z I_{i} / w_{*}$ that is quite consistent with the bounds shown in Tables 2 and 3.

\section{Conclusions}

There are a number of important findings from the tracer study that are of direct relevance to air pollution studies, first of which is that close to the shoreline different stabilities can exist above the land and water surfaces. Under these conditions atmospheric stability cannot be easily determined in terms of conventional classifications. A second finding is that the
$K$-theory model. The objective of this section is to present a simple formulation that produces transport times consistent with observed fumigation rates. Some recent work by Crane et al. (1977) and McRae et al. (1981) indicates that vertical eddy diffusivity profiles for unstable conditions can be scaled by a single profile of the form

$$
K_{z z}=w_{*} Z_{i} f\left(\frac{z}{Z_{i}}\right) .
$$

Lamb et al. (1975) derived an expression for $f$ using the numerical turbulence model of Deardorff (1970). The profile adopted by McRae et al. (1981) is given by

presence of convective activity can cause downmixing or fumigation of material that can return the next day as a significant increment to the onshore ground-level concentration. The process by which this occurs is as follows. During the night, cool stable air is advected out over the ocean. When this air encounters the warmer ocean surface convective mixing begins to erode the stable layer. Once the internal boundary layer has grown to the height of the plume the tracer material, entrained at the top of the mixed layer, is rapidly fumigated to the surface. The characteristic mixing time, inferred from the concentration records, is consistent with an estimate based on the convective time scale $\lambda=Z_{i} / w_{*}$ that, for the conditions of the experiment, was $\sim 20 \mathrm{~min}$. 


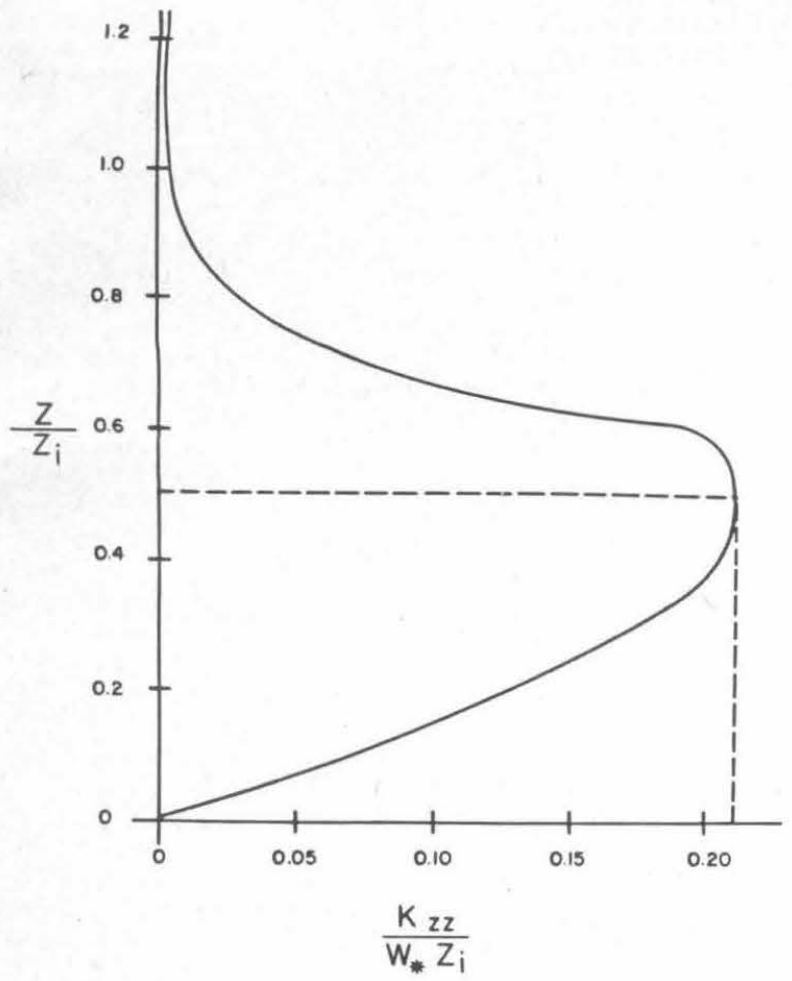

FIG. 6. Vertical turbulent diffusivity profile for unstable conditions (source, McRae et al., 1981).

Understanding of these mixing processes and convective activity over the ocean will improve the ability to predict atmospheric dispersion in coastline environments.

Acknowledgments. This work was supported by the California Air Resources Board under contracts A5-187-30, A5-046-87 and A7-187-30. The assistance of Gordon Schacher of the Naval Postgraduate School, who supplied descriptions of data reduction procedures and measurement equipment, and Charles Bennett of the California Air Resources Board is appreciated.

\section{REFERENCES}

Agee, E. M., and T. S. Chen, 1973: A model for investigating eddy viscosity effects on mesoscale convection. J. Atmos. Sci., 30, 180-189.

Arnold, A., and J. R. Rowland, 1976: Fine scale observation of free convection in the atmospheric boundary layer. Preprints Third Symp. Atmospheric Turbulence Diffusion and Air Quality, Raleigh, Amer. Meteor. Soc., 1-8.

, T. G. Konrad, J. H. Richter, D. R. Jensen and V. R. Noonkester, 1975: Simultaneous observation of clear air convection by a pulse radar, an FM-CW radar, an acoustic sounder and an instrumented aircraft. Preprints 16th Radar Meteorology Conf., Houston, Amer. Meteor. Soc., 290-295.

Ball, F. K., 1960: Control of inversion height by surface heating. Quart. J. Roy. Meteor. Soc., 86, 483-494.
Briggs, G. A., 1969: Plume Rise. Atomic Energy Commission Review Series, 81 pp. [NTIS TID-25075].

_ 1975: Plume rise predictions. Lectures on Air Pollution and Environmental Impact Analysis, D. A. Haugen, Ed. Amer. Meteor. Soc., 59-111.

Busch, N. E., 1977: Fluxes in the surface boundary layers over the sea. Proceedings of a NATO Advanced Study Institute, Urbino, Italy, (1975), Pergamon Press, 72-91.

Businger, J. A., 1975: Interactions of sea and atmosphere. Rev. Geophys. Space Phys., 13, 720-726, 817-822.

—, J. C. Wyngaard, Y. Izumi and E. F. Bradley, 1971: Fluxprofile relationship in the atmospheric surface layer. J. Atmos. Sci., 28, 181-189.

Caughey, S. J., B. A. Crease, D. N. Asmakopoulos and R. S. Cole, 1978: Quantitative bistatic acoustic sounding of atmospheric boundary layer. Quart. J. Roy. Meteor. Soc., 104, $147-161$.

Crane, G., H. A. Panofsky and O. Zeman, 1977: A model for dispersion from area sources in convective turbulence. Atmos. Environ., 11, 893-900.

Deardorff, J. W., 1970: A three-dimensional numerical investigation of the idealized planetary boundary layer. Geophys. Fluid Dyn., 1, 377-410.

_ 1972: Numerical investigation of neutral and unstable planetary boundary layers. J. Atmos. Sci., 29, 91-115.

_ 1978: Prediction of convective mixed-layer entrainment for realistic capping inversion structure. J. Atmos. Sci., 36, 424-436.

, G. E. Willis and B. H. Stockton, 1980: Laboratory studies of the entrainment zone of a convectively mixed layer. $J$. Fluid Mech., 100, 41-64.

Dietz, R. N., and E. A. Coté, 1973: Tracing atmospheric pollutants by gas chromatographic determination of sulfur hexafluoride. Environ. Sci. Tech., 7, 338-342.

Drivas, P. J., and F. H. Shair, 1974: A tracer study of pollutant transport and dispersion in the Los Angeles area. Atmos. Environ., 8, 1155-1163.

Frisch, A. S., R. B. Chadwick, W. R. Moninger and J. M. Young, 1975: Observation of boundary layer convection cells measured by dual-Doppler radar and echosounder and by microbarograph array. Bound.-Layer Meteor., 3, 199-226.

Hardy, K. R., and H. Ottersten, 1969: Radar investigation of convective patterns in the clear atmosphere. J. Atmos. Sci., 26, 666-672.

Heidt, F. D., 1977: The growth of the mixed layer in a stratified fluid due to penetrative convection. Bound.-Layer Meteor., $12,439-461$.

Houlihan, T. M., K. L. Davidson, C. W. Fairall and G. E. Schacher, 1978: Experimental aspects of a shipboard system used in investigation of overwater turbulence and profile relationships. Naval Postgraduate School Rep. No. NPS6178-001, 254 pp.

Kaimal, J. C., J. C. Wyngaard, D. A. Haugen, O. H. Coté and Y. Izumi, 1976: Turbulence structure in the convective boundary layer. J. Atmos. Sci., 33, 2152-2169.

Kraus, E. B., 1972: Atmosphere-Ocean Interaction. Clarendon Press, 275 pp.

Konrad, T. G., 1970: The dynamics of the convective process in clear air as seen by radar. J. Atmos. Sci., 27, 1138-1147.

Lamb, B. K., A. Lorenzen and F. H. Shair, 1978a: Atmospheric dispersion within coastal regions-Part I. Tracer study of power plant emissions from the Oxnard Plain. Atmos. Environ., 12, 2089-2100.

- F. H. Shair and T. B. Smith, 1978b: Atmospheric dispersion within coastal regions-Part II. Tracer study of industrial emissions in the California Delta region. Atmos. Environ., 12, 2101-2118.

Lamb, R. G., H. W. Chen and J. H. Seinfeld, 1975: Numericoempirical analysis of atmospheric diffusion theories. $J$. Atmos. Sci., 32, 1754-1807. 
Lyons, W. A., 1975: Turbulent diffusion and pollutant transport in shoreline environments. Lectures on Air Pollution and Environmental Impact Analysis, D. A. Haugen, Ed., Amer. Meteor. Soc., 59-111.

Manins, P. C., 1977: Fumigation and a laboratory experiment. Weather, June, 221-228.

McBean, G. A., and J. I. MacPherson, 1975: Turbulence above Lake Ontario: velocity and scalar statistics. Bound.-Layer Meteor., 10, 181-197.

McRae, G. J., W. R. Goodin and J. H. Seinfeld, 1981: Development of a second generation mathematical model for urban air pollution: I Model formulation. Atmos. Environ., (in press).

Misra, P. K., 1980: Dispersion from tall stacks into a shore line environment. Atmos. Environ., 14, 397-400.

Monin, A. S., and A. M. Yaglom, 1971: Statistical Fluid Mechanics: Mechanics of Turbulence, Vol. I. MIT Press, $769 \mathrm{pp}$.

Orgill, M. M., 1981: Atmospheric studies in complex terrain: A planning guide for future studies. Rep. PNL-3656, Pacific Northwest Laboratories, Richland, WA, U.S. Department of Energy Contract DE-AC06-76RLO 1830.

Raynor, G. S., P. Michael and S. SethuRaman, 1980: Meteorological measurement methods and diffusion models for use at coastal nuclear reactor sites. Nuclear Safety, 21, 749-765.

Schacher, G. E., K. L. Davidson and C. W. Fairall, 1980: Atmospheric marine boundary layer mixing rates in the California coastal region. Naval Postgraduate School Rep. No. NPS6180-003, $115 \mathrm{pp}$.

, C. W. Fairall, K. L. Davidson and T. M. Houlihan, 1978: Experimental investigation of the marine boundary layer in support of air pollution studies in the Los Angeles air basin. Naval Postgraduate School Rep. No. NPS61-78-002, 257 pp.
Schatzmann, M., 1979: An integral model of plume rise. Atmos. Environ., 13, 721-731.

Shair, F. H., E. Sasaki, D. Carlan, G. R. Cass, W. R. Goodin, J. Edinger and G. E. Schacher, 1981: Transport and dispersion of airborne pollutants associated with the land breezesea breeze system. Atmos. Environ. (in press).

Simmonds, P. G., G. R. Shoemake, J. E. Lovelock and H. C. Lord, 1972: Improvements in the determination of sulfur hexafluoride for use as a meteorological tracer. Anal. Chem., 44, $860-863$.

Smith, T. B., S. L. Marsh, W. H. White, T. N. Jerskey, R. G. Lamb, P. A. Durbin and J. P. Killus, 1976: Analysis of the data from the three-dimensional gradient study. Final Report to the California Air Resources Board under Contracts ARB-4-051 and ARB-4-250, Meteorology Research, Inc., Pasadena, and Systems Applications, Inc., San Rafael, 124 pp.

Stull, R. B., 1973: Inversion rise model based on penetration convection. J. Atmos. Sci., 30, 1092-1099.

Venkatram, A., 1976: Internal boundary layer development and fumigation. Atmos. Environ., 11, 479-482.

Willis, G. E., and J. W. Deardorff, 1976a: Visual observations of horizontal planforms of penetration convection. Preprints Third Symp. Atmospheric Turbulence Diffusion and Air Quality, Raleigh, Amer. Meteor. Soc., 1-8.

$\ldots$, and $-1976 \mathrm{~b}$ : A laboratory model of diffusion into the convective planetary boundary layer. Quart.J. Roy. Meteor. Soc., 102, 427-445.

Zeman, O., and H. Tennekes, 1977: Parameterization of the turbulent energy budget at the top of the daytime atmospheric boundary layer. J. Atmos. Sci., 34, 111-123. 